\title{
Educação Infantil Pública Municipal em Florianópolis: um estudo da arquitetura escolar a partir de documentos iconográficos (1976 a 1987)
}

\begin{abstract}
Resumo
$\mathrm{O}$ artigo tem como objetivo analisar, do ponto de vista histórico, a arquitetura e o espaço escolar ${ }^{1}$ das instituições de Educação Infantil da Rede Pública do Município de Florianópolis, no período de 1976 a $1987^{2}$. Tal análise das primeiras instituições dessa rede pode contribuir com o processo de investigação da história da educação no município pela estreita relação, evidenciada por outros estudos, entre arquitetura escolar e pedagogia. O recorte histórico se justifica pelo fato de 1976 marcar o ano em que o poder público local inicia o atendimento às crianças pequenas, e o ano de 1987, por haver precedido a promulgação da Constituição federal de 1988, que consagrou o direito da criança a esse atendimento. $\mathrm{O}$ estudo parte de diferentes fontes - com especial atenção nos documentos iconográficos - a respeito da maneira como os espaços em referência foram ocupados e habitados por adultos e crianças, e investiga a cultura material escolar. Com uma leitura fundamentada nesses contextos, quer-se decifrar os significados das práticas educativas aplicadas e materializadas na trajetória das instituições para a infância, na construção histórica da ocupação dos seus espaços e, em certa medida, nas escolhas e decisões que marcam a época. Como resultado, consolida-se a convicção de que a arquitetura não é neutra e deve ser considerada nos projetos educacionais.
\end{abstract}

Palavras-chave: Arquitetura escolar. Fotografia. Educação Infantil.

\author{
Adriana de Souza Broering \\ Mestranda em Educação e \\ Supervisora Escolar II, na Creche \\ Nossa Senhora Aparecida, em \\ Florianópolis - SC. \\ adrianabroering@gmail.com
}

\section{Patrícia Regina Silveira de Sá Bran \\ Mestrado em Educação pela \\ Universidade do Estado de Santa \\ Catarina. Supervisora de Educação \\ Infantil na Rede Municipal de Ensino \\ de Florianópolis - SC. \\ patricia.sabrant@gmail}

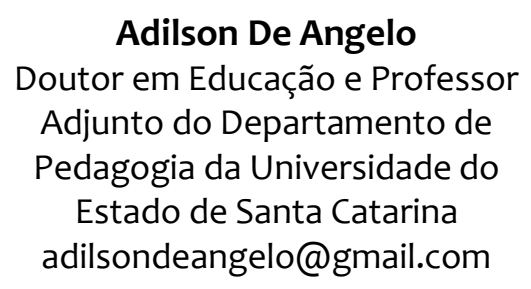

\begin{abstract}
10 adjetivo escolar está sendo aqui utilizado para ajudar a evidenciar o propósito dessas instituições em prestar determinado tipo de educação. Na defesa desta ideia, Moysés Kuhlmann Jr. nos indica que "o adjetivo escolar não definiria de antemão um modelo de organização pedagógica para a instituição. Definiria a natureza da mesma - educacional -, no interior da qual se encontrariam estruturas e objetivos de ordens diversas: a creche, a pré-escola, a escola de ensino fundamental, a escola técnica (de processamento de dados, de análises laboratoriais, de construção civil e outras), etc." (KUHLMANN JR., 1999, p. 61-62).

2Uma primeira versão deste trabalho, sob o título "Arquitetura e espaço e escolar: história da educação infantil pública em Florianópolis de 196 a 1987” foi apresentada no IX Congresso Luso-Brasileiro da História da Educação, promovido pela Secção de História da Educação (Portugal) e pelo GT de História da Educação da Associação Nacional de Pós-Graduação e Pesquisa em Educação - Anped - e pela Sociedade Brasileira de História da Educação (Brasil), realizado na Universidade de Lisboa entre os dia 12 e 15 de julho de 2012.
\end{abstract}




\title{
Para citar este artigo:
}

BOERING, Adriana de Souza; BRAN, Patrícia Regina Silveira de Sá; De Angelo, Adilson. Educação Infantil

Pública Municipal em Florianópolis: um estudo da arquitetura escolar a partir de documentos iconográficos (1976 a 1987). Revista Linhas, Florianópolis, v. 14, n. 26, jan./jun. 2013. p. 42 - 60.

\section{Public Early Childhood Education in Florianópolis city: a study of architecture schoolfrom iconographic documents}

\begin{abstract}
This paper aims at an interpretation of the historical nature about the architecture and the school environment of the public childhood educational institutions in the city of Florianópolis, in the period 1976-1987. When analyzing the architecture and the school environment of the first institutions of this city, it is possible to realize a historical research of education in this city, mainly though the closely relationship showed by other studies, between school architecture and pedagogy. The historical study period is justified mainly because the year of 1976 highlights the period that the local public government starts the small children care, and the year of 1987 is immediately before the year where the 1988 Federal Constitution was enacted and it was guaranteed the children's right care. The presented analysis is built from different sources - with special attention to iconographic documents - about how these spaces were occupied and inhabited by adults and children, and it researches the material culture school. The results show that the architecture is not neutral and should be considered in educational projects, based on a reading within these contexts and, it attempts to understand the meaning of educational practice applied and materialized in the trajectory of these institutions for children, in the historical occupation of these areas, and, in the choices and decisions that from this era.
\end{abstract}

Keywords: Scholar Architecture. Photography. Early childhood education. 


\section{Introdução}

Com esta pesquisa ${ }^{3}$, buscamos refletir, em perspectiva histórica, sobre as primeiras instituições criadas para atender às crianças pequenas no município de Florianópolis, no que diz respeito à arquitetura e o espaço escolar da educação infantil da Rede Municipal de Ensino Infantil (RME), ${ }^{4}$ no período de 1976 a 1987. Pretendemos com tal análise contribuir com o processo de investigação da história da educação no município pela estreita relação, evidenciada por outros estudos, entre arquitetura escolar e pedagogia. Por considerar importante para a investigação da História da Educação a análise destes aspectos buscamos, em particular, desvendar a cultura material escolar implícita nessas construções, sob o ponto de vista da apropriação, interpretação e reinterpretação do espaço em sua funcionalidade.

No Brasil, as instituições destinadas ao acolhimento das crianças pequenas surgiram no século XIX, com a criação dos jardins de infância, marcadamente para atender às classes abastadas. O século XX assistiu à criação de creches, instituições com a finalidade de atender a uma clientela bastante diferenciada da atendida nos jardins de infância, pertencentes à classe trabalhadora, econômica e socialmente desassistida .

Oliveira (2002, p. 92) aponta que o Brasil importou como primeiro modelo de instituição para este nível, no final do século XIX, "o modelo europeu dos Jardins de Infância" criado por Froebel, ${ }^{5}$ destinado às crianças das classes mais favorecidas. Esta foi

\footnotetext{
3 Este trabalho apresenta os resultados parciais de pesquisa em andamento, realizada pela mestranda Adriana de Souza Broering, junto ao Programa de Pós-Graduação em Educação (PPGE), do Centro de Ciências Humanas e da Educação da Universidade do Estado de Santa Catarina (Udesc), na Linha de História e Historiografia da Educação. A parceria da elaboração deste artigo se efetiva pelo interesse em história da Educação Infantil da Rede Municipal de Florianópolis de parte de Patrícia Regina Silveira de Sá Brant, mestra pelo mesmo Programa de Pós-Graduação, com pesquisa nessa área, e de Adilson De Angelo, professor desta Universidade, coordenador do Projeto de Extensão "Cá Entre Nós: Viver, conviver e aprender a Educação Infantil", que se constituiu a partir das reflexões geradas pela pesquisa da mestranda Adriana Souza Broering.
}

4 O adjetivo escolar está sendo aqui utilizado para ajudar a evidenciar o propósito dessas instituições em prestar determinado tipo de educação. Na defesa desta ideia, Moysés Kuhlmann Jr. nos indica que "o adjetivo escolar não definiria de antemão um modelo de organização pedagógica para a instituição. Definiria a natureza da mesma - educacional -, no interior da qual se encontrariam estruturas e objetivos de ordens diversas: a creche, a pré-escola, a escola de ensino fundamental, a escola técnica (de processamento de dados, de análises laboratoriais, de construção civil e outras), etc." (KUHLMANN JR., 1999, p. 61-62).

${ }^{5}$ O pedagogo alemão Friedrich Wilhelm August Froebel $(1782$ - 1852) foi o fundador dos jardins da infância os Kindergartens - que serviram de modelo para a educação pré-escolar, propagado internacionalmente 
a posição tomada pelas elites do País que, assim, se apropriaram do modelo e do enfoque educacional trazido pela renovação pedagógica escolanovista, enquanto às crianças das classes populares foram destinados, na época, os parques infantis e as creches, com enfoque no cuidado e na guarda das crianças. Aí se embute uma concepção educacional: assistencialismo, configurado como proposta educacional já na constituição dessas instituições (KUHLMANN JR., 2005).

A educação infantil pública no município de Florianópolis ${ }^{6}$ teve início no ano de 1976, com a criação do Projeto Núcleos de Educação Infantil, pelo Departamento de Educação da então Secretaria de Educação, Saúde e Assistência Social (Sesas). Segundo dados já levantados, a rede de Educação Infantil da Prefeitura Municipal de Florianópolis se diferencia, no cenário nacional, desde o projeto inicial de sua criação, por sua vinculação direta com a Secretaria de Educação ${ }^{7}$. Outro aspecto diferenciador, apontado por Ostetto (2000), é o fato de os profissionais contratados serem professoras por formação. Não podemos desconsiderar que naquele período ainda não havia legislação que assegurasse os direitos das crianças - reconhecendo-as como cidadãs de direitos -, conquistas legais estabelecidas a partir da Constituição Federal de $1988^{8}$. A escolha do recorte histórico justifica-se por ter sido 1976 o ano em que o poder público local dá início ao atendimento às crianças de zero a seis anos, e, o de 1987, o que antecede à promulgação da Constituição de 1988.

\footnotetext{
(KULHMANN JR., 2010).

${ }^{6}$ Referimo-nos à educação infantil sob a tutela da Rede Municipal de Ensino (RME) de Florianópolis.

${ }^{7}$ Denominada, inicialmente, de Secretaria de Educação, Saúde e Assistência Social (Sesas); a partir de 1986, de Secretaria Municipal de Educação (SME).

${ }^{8}$ A Constituição da República Federativa do Brasil de 1988 é um marco histórico na educação infantil, pois prevê a educação como direito de todos e a classifica como um dever do Estado. A partir da Constituição de 1988, sucederam-se outras importantes conquistas legais. Na década de 1990, considerou-se um grande avanço o reconhecimento das crianças em suas especificidades e como cidadãs pela promulgação do Estatuto da Criança e do Adolescente (BRASIL, 1990). Ressalta-se, nos anos seguintes, a participação da Coordenadoria de Educação Infantil (Coedi) do MEC que, por meio de encontros, pesquisas e publicações, promoveu a articulação de uma política nacional que preparou a aprovação da nova LDB (BRASIL, 1996; OLIVEIRA, 2002), a qual afirma a educação infantil como etapa inicial da educação básica. Isso implica reconhecimento e valorização da educação infantil de parte dos profissionais que atuam neste nível, bem como das crianças pequenas.
} 
Os dados indicam que a trajetória da educação infantil na rede pública do município de Florianópolis não foge ao fluxo seguido pela história da educação infantil nos demais municípios do Brasil, no que tange a origem, regulamentações legais, diretrizes, currículos e programações:

\begin{abstract}
Inicialmente cumprindo a função primordial de atendimento às crianças chamadas "carentes", guardando-as e alimentando-as enquanto suas mães trabalhavam fora do lar, vai mesclando-se no decorrer de seus vinte anos de existência, com um trabalho de preparação para a escola de primeiro grau, onde os exercícios de coordenação motora predominam. Vai, enfim, avançando para concepções próprias de seu tempo, como por exemplo, a defesa do desenvolvimento e da autonomia como metas da educação, nos 90 (OSTETTO, 2000, p. 28).
\end{abstract}

Historicamente, podemos identificar que, a partir da criação da educação infantil na Rede Municipal de Ensino (RME), na década de 1970, no que se refere ao espaço escolar, muitos foram os posicionamentos assumidos quanto a configurações arquitetônicas, tamanho e diversificação para fins de expansão e acomodação de especificidades. No presente estudo, buscamos, pela análise de documentos oficiais, legislações, reportagens da imprensa e, em especial, de imagens - percebidas como importantes documentos históricos -, identificar o discurso e a cultura escolar presentes, com a finalidade de contribuir com a análise da história das instituições de crianças pequenas no município de Florianópolis.

\title{
Fotografias: a história nas imagens
}

Existem múltiplos caminhos para entender uma imagem, mas é preciso, antes de tudo, considerar sua vinculação com o contexto sociopolítico, cultural e pedagógico de um período. Com uma leitura fundamentada no contexto histórico e na articulação entre o imagético e os documentos oficiais - antes analisados como única possibilidade de revelar verdades sobre os fatos históricos -, vão se cruzando diversas fontes, revelando detalhes e peculiaridades, antes não percebidos ou estudados. As imagens fotográficas do universus scholaris utilizadas como fonte de pesquisa histórica das instituições educacionais "têm demonstrado potencial analítico suficiente para colaborar na busca e 
organização de compreensões e explicações acerca da cultura escolar manifestada nos ambientes em que ela interage" (BENCOSTTA, 2002, p. 24).

Buscamos nas imagens da RME a possibilidade de cruzamento com outras fontes para a melhor compreensão da trajetória histórica do objeto deste estudo. Nessa perspectiva, a metodologia segue a ideia de que, "para compreender melhor as imagens, tanto a sua especificidade quanto as mensagens que veiculam, é necessário um esforço mínimo de análise" (JOLY, 1996, p. 28). As fotografias, por apresentarem uma iconologia complexa, necessitam de interpretação, uma vez que tanto podem ser utilizadas como informantes na reconstituição do passado, como “matéria para construção de ficções”. É um desafio intelectual que exige conhecimento da "realidade própria do tema registrado na imagem, como em relação à realidade que lhe circunscreveu no tempo e no espaço, na tentativa de equacionarmos de inúmeros elos perdidos da cadeia de fotos" (KOSSOY, 1998, p. 44). Embora a fotografia seja um instrumento relativamente novo como fonte de investigação para a história, a análise das imagens de algumas instituições e dos espaços utilizados para educar e cuidar das crianças, cruzadas com as plantas arquitetônicas e outras fontes, permitem revelar outros ângulos e desencadeiam novas interpretações da trajetória da educação infantil da RME de Florianópolis.

Figura 1 - Uma velha igreja cedida para atender as crianças pequenas da periferia: A "nova escola" (Vista frontal da capela de Santo Antônio e Maria Gorete em 1976)

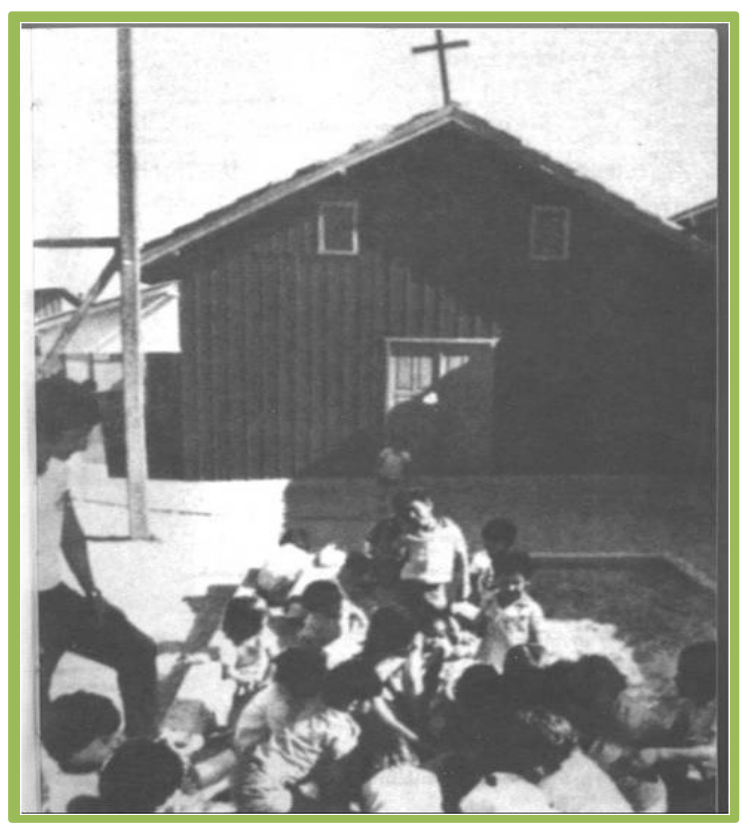

Fonte: Ostetto, (2000, contracapa). 
Na imagem "garimpada” pela professora Luciana Ostetto (2000), segundo suas próprias palavras, a velha igreja de madeira, adaptada para ser um novo espaço educativo, acolhe o nascimento da primeira instituição de educação infantil da RME de Florianópolis, o Núcleo de Educação Infantil - NEI - no bairro Coloninha, situado no continente. Hoje, olhar para essa imagem pode causar certo estranhamento, mas o aproveitamento desse tipo de espaço - lugares ociosos da comunidade - para o atendimento pré-escolar era estimulado na época pelo então Ministério da Educação e Cultura (MEC), pois era considerado com estrutura física suficiente para atender às crianças em idade pré-escolar. Esta orientação foi posta em prática em Florianópolis, demonstrando que, em certa medida, a educação infantil na rede municipal acompanha a trajetória histórica do Brasil. Observa-se, na década de 1970, uma rápida expansão dessa cobertura, sustentando o discurso corrente de encontrar soluções em curto prazo e de baixo custo 9 .

É preciso estar alerta ao transitar pela história da educação para trazer novos significados e novas perspectivas ao cenário atual. É importante estudar as determinações legais e os encaminhamentos adotados na implantação dessa rede para indagar do que subjaz nas orientações oficiais do MEC. A velha igreja utilizada como espaço educacional foi efetiva quanto à intenção de "salvar" as crianças carentes?

Com o propósito do atendimento, foi necessário reorganizar e adaptar o espaço físico da velha igreja, seguindo as orientações da coordenadora que assumiu o Projeto Núcleo de Educação Infantil:

Onde era o lugar dos fiéis, nós dividimos em dois, fizemos duas salas grandes. [...] onde o padre rezava a missa, aquela parte mais alta, nós fizemos ali a sala da diretora e um depósito onde ficavam as comidas. $\mathrm{E}$ onde canta o coro, lá em cima, então era o depósito. Todo material da pré-escola, papel, tinta, ficava tudo lá em cima (OSTETTO, 2000, p. 48).

\footnotetext{
${ }^{9} \mathrm{Na}$ década de 1970, no Brasil, o atendimento à criança de zero a seis anos, por ocasião da grande expansão da pré-escola promovida pelo governo federal, é pautado em programas de baixo custo (CAMPOS, 1985; ROSEMBERG, 1992).
} 
Podemos verificar que o mesmo local foi estrategicamente ocupado pelo padre e pela direção. Para este caso, pode não ter havido uma intenção explícita, mas não podemos desconsiderar que "a localização e a disposição física dos espaços destinados a uma finalidade ou função determinada no seio de qualquer instituição refletem seja sua importância, seja a concepção que se tem sobre da natureza, o papel e as tarefas destinadas a tal função" (VIÑAO FRAGO, 2005, p. 15). Diante desse princípio, defendido pelo autor, caberia indagar se seria casual a sala da direção estar localizada na parte mais alta onde antes figurava outra autoridade. Com que objetivo se posicionaria ali a direção? Visão privilegiada? Controle? Exibição de superioridade? Questões que não podem ser desconsideradas quando desejamos compreender a cultura escolar, pois, tanto a divisão, a distribuição, como a ocupação dos espaços devem ser ponderados nesta análise.

A análise de outras materialidades também colabora nesta compreensão. No caso da instituição que estava sendo formada, entre os materiais adquiridos e citados pela coordenadora, não se faz alusão a brinquedos. Haveria ou não brinquedos nessa primeira instituição pública para a infância florianopolitana? Que espaço-tempo se reservava ao lúdico? Se transitarmos por vários momentos históricos, embora, como já evidenciamos, tenha havido uma diferenciação da trajetória da educação infantil em Florianópolis em relação a outras realidades, ao voltar para a imagem, que mais é possível perceber?

A construção de madeira, ao fundo da imagem das crianças, tem duas pequenas janelas na parte superior; embaixo, ao centro, uma porta; no ponto mais alto e central do telhado, há fixada uma cruz. Em frente a esse cenário, há crianças pequenas brincando em um "tanque de areia" sob a observação de um adulto. Tomemos como ponto de partida, para efeito de análise, a presença da cruz que, mesmo não sendo grande, marca o cuidado do fotógrafo em mantê-la no enquadramento da sua máquina na hora do registro. Por que ela nos toca? Mesmo que o local não continue mais como igreja, permanecem no foco, e como pano de fundo para a imagem das crianças, a cruz e, com ela, toda a simbologia nela representada.

Também poderíamos destacar o fato de as crianças estarem brincando. Seria essa a intenção do fotógrafo? Seria uma matéria encomendada? A foto ilustra a notícia no jornal que informa a abertura de 96 vagas na educação pré-escolar municipal (OSTETTO, 
2000). Tais escolhas - o foco, o posicionamento do fotógrafo, a seleção da cena - não são neutras e as reflexões que suscitam acerca desta e de outras imagens recolhidas nesses espaços educativos seguem o que Souza (2001, p. 77) levanta como questões específicas sobre o uso da fotografia como fonte documental: "Quando a vida escolar se torna tema do olhar fotográfico? Quando e por que se fotografam cenas escolares? [...]. O que nos revelam essas imagens?" São reflexões que abrangem questões amplas e pertinentes considerações, que certamente não se pretendem esgotar neste artigo. Vale registrar nossa compreensão de que as fotografias, analisadas como documentação visual que preserva e transmite a memória coletiva daquele grupo, podem contribuir com respostas às questões levantadas na pesquisa, como também podem levantar novas e importantes indagações. O registro imagético, em análise, juntamente com os relatos da coordenadora do projeto de implantação da educação infantil da RME de Florianópolis (OSTETTO, 2000), contribui para o entendimento dos significados visíveis e ocultos das práticas educativas ali realizadas.

\section{A primeira instituição construída pelo poder público para a educação infantil: Culturas escolares aparentes?}

Os dados e as outras fontes investigadas para esta análise histórica, que inclui a arquitetura e o espaço escolar de instituições de educação infantil, pretendem destacar a forma como ocupados e habitados por adultos e crianças e a cultura escolar naquele período (DUSSEL; CARUSO, 2003).

Em 1979, foi construído o primeiro prédio específico para atendimento de crianças pequenas da RME de Florianópolis. Esta construção foi bastante significativa, pois o antigo Núcleo de Educação Infantil (NEI) Coloninha, que funcionava na velha igreja, mudou-se, sendo absorvido por esse novo espaço que passou a se caracterizar como creche, o que sugere preocupação com a arquitetura, uma vez que as orientações oficiais nacionais indicavam que a ocupação dos espaços ociosos era legítima. A creche representou também uma nova modalidade de atendimento, pela ampliação do tempo de permanência de 4 para 12 horas. As crianças de três meses a três anos, que antes não 
recebiam atendimento, passaram a ser acolhidas em período integral e as de quatro a anos, meio período (OSTETTO, 2000).

A segunda fotografia, selecionada para o artigo, apresenta uma cena em frente à Creche Professora Maria Barreiros, primeiro espaço construído especialmente para a educação infantil do município de Florianópolis, situada no bairro Coloninha, no continente.

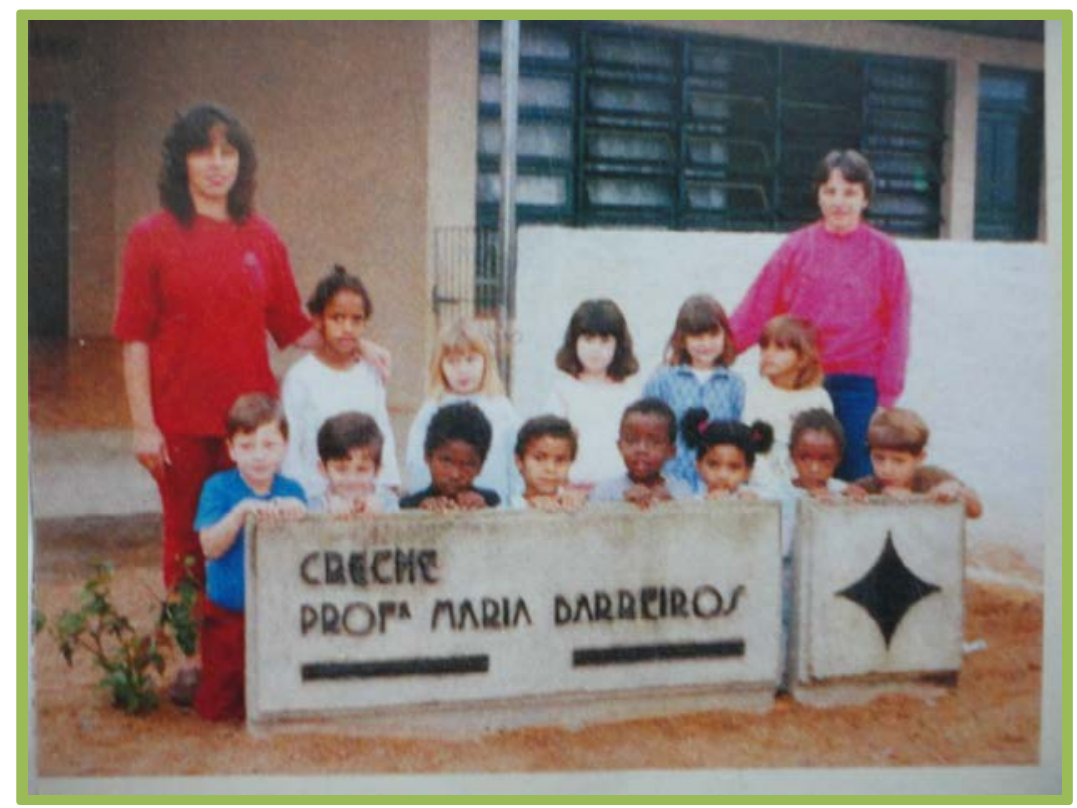

Figura 2: Crianças e profissionais de educação infantil em frente à Creche Professora Maria Barreiros, em 1979.

Fonte: Arquivo da instituição, cedido à Secretaria Municipal de Educação nas comemorações dos 30 anos da Educação Infantil no Município de Florianópolis.

A fotografia mostra 13 crianças e dois adultos. Oito crianças estão ajoelhadas atrás da placa que ostenta o nome da creche, por sinal, todos os meninos, embora haja também algumas meninas, enquanto todas as demais estão em pé. Todas as crianças ajoelhadas estão com as duas mãos em cima da placa. As duas profissionais possivelmente uma professora e uma auxiliar de sala -, posicionaram-se nas laterais e têm os braços apoiados sobre as crianças. Essa organização, no entender de Souza (2001), é “expressão da ordem escolar”. Não somente na estrutura hierárquica, uma vez que as professoras aparecem como guardiãs, mas também pelo sentido de "obediência" na postura ensaiada das crianças com expressões faciais muito sérias. Poderia ser uma ordem pensada pelos adultos, ou uma imposição, como em outros registros de classe já 
observados, nos quais as instituições escolares desejam afirmar que "a escola é o espaço da ordem, da obediência, do silêncio e da disciplina, cuja representação é confirmada nesse tipo de imagem" (SOUZA, 2001, p. 90).

Segundo a autora, há muitos registros de cenas escolares que apresentam esse ritual de compenetração, bastante característico na primeira metade do século XX, sendo difícil encontrar registros descontraídos antes da década de 1920. Portanto, como esta, outras fotografias escolares podem ajudar a revelar os valores e a cultura escolar. "Elas são a expressão da forma escolar - uma maneira de se comportar na escola, apresentações, valores, normas e símbolos considerados legítimos. Elas representam singularidades e identidades compartilhadas" (Ibid. p. 81). Analisar a cultura escolar requer pensar os espaços educativos e, ainda, a forma como os sujeitos envolvidos professores, demais profissionais e adultos que convivem com as crianças - se relacionam entre eles no e com o espaço.

A imagem fotográfica do prédio, especialmente construído para o atendimento das crianças, também instigou a curiosidade no sentido de buscar identificar, por outras fontes, em que medida significava uma alteração, ou não, nas práticas educativas nos espaços, agora devidamente projetados e construídos para serem habitados por adultos e crianças. Gonçalves (1996, p. 212) faz importantes reflexões a respeito: "Novas significações do prédio escolar não significam, no entanto, novas relações pedagógicas no seu interior. Podem-se ter velhas relações pedagógicas em um prédio novo e novas relações pedagógicas num velho prédio escolar". Tais questões, desencadeadas pela análise da imagem, tanto podem corresponder efetivamente ao que parece, como podem apenas ser uma representação utilizada para aquele momento. É fato que as crianças, que antes frequentavam a igrejinha, agora tinham um novo prédio construído especialmente para elas - "Creche Professora Maria Barreiros". Mudanças no nome, no espaço, na faixa etária atendida e no tempo de permanência das crianças. O que mais teria mudado?

Não tivemos acesso à planta dessa instituição, mas, nas entrevistas da pesquisa realizada por Ostetto (2000), fica claro que três das salas construídas eram para as crianças menores. Segundo os depoimentos recolhidos pela pesquisadora, devido ao fato 
de serem muito pequenas, mais tarde passaram por uma reforma, sendo transformadas em uma única sala. Estes dados são significativos por apresentar o primeiro espaço construído especialmente para educar crianças. Entendendo que a arquitetura deve levar em conta o espaço interior, os fatos relatados evidenciam que as alterações seguiram na busca por espaços mais apropriados.

Esses e outros dados sobre a internalidade do espaço educativo informam sobre as marcas das práticas incorporadas pela cultura escolar ali vivenciada. Pensando na cultura escolar, o que elas indicariam? Entendendo a cultura escolar como o conjunto de:

[...] prácticas y conductas, modos de vida, hábitos y ritos - la historia cotidiana del hacer escolar -, objetos materiales - función, uso, distribuicón en el espacio, materialidad física, simbologia, introducción, transformación, desaparición.... -, y modos de pensar, así como significados e ideas compartilhadas. Alguien dirá: todo. Y sí, es cierto, la cultura escolar es toda la vida escolar [...] (VINÃO FRAGO, 1995, p. 68-69). ${ }^{10}$

Como neste caso, na falta de elementos para cruzar permanece a ambivalência sobre a concepção de educação infantil que ela parece retratar. Ter-se-ia preservado a representação da escola tradicional, como aconteceu com a fotografia? Ou "somente a fotografia sobrevive" (KOSSOY, 1998, p. 45)?

\section{Uma arquitetura reproduzida: O "PADRÃO IPUF"}

Um dos raros documentos oficiais do Ministério da Educação encontrados sobre a arquitetura escolar cita:

Mesmo reconhecendo a importância desse enfoque sobre a temática Arquitetura Escolar, entendemos que ainda existe uma lacuna entre a reflexão teórica e a realidade concreta das edificações escolares, especialmente as destinadas à Educação Infantil [...] (BRASIL, 2004, p. 5).

Em nove anos de funcionamento da educação infantil da RME, observa-se um crescimento muito rápido relativamente à construção de novas edificações. Em 1976,

\footnotetext{
${ }^{10}[. .$.$] práticas e condutas, modos de vida, hábitos e ritos - a história cotidiana do agir escolar -, objetos$ materiais - função, uso, distribuição no espaço, materialidade física, simbologia, introdução, transformação, desaparecimento... -, e maneiras de pensar, assim como significados e ideias compartilhadas. Alguém dirá: tudo. Sim, com certeza, a cultura escolar é toda a vida escolar [...] (Tradução nossa).
} 
havia apenas uma instituição; em 1979, havia mais duas e, em 1987, o programa já contava com 25 núcleos de educação infantil (NEIs) e dez creches (OSTETTO, 2000). Cabe esclarecer que, para a Lei de Diretrizes e Bases de 1996, creches são instituições que atendem a crianças de zero a três anos. Na rede municipal de Florianópolis, entretanto, creches são instituições com atendimento integral. Desta forma, no ano de 1987, anterior ao da promulgação da Constituição Federal, pela qual foi instituído o dever desse atendimento, o município de Florianópolis já contava com 35 instituições em pleno funcionamento, atendendo aproximadamente a 2.098 crianças (OSTETTO, 2000).

No mapeamento realizado por Agostinho (2003), a partir do contato com os projetos arquitetônicos de 32 creches da RME, existentes até 2002, a pesquisadora identifica cinco padrões de configuração das edificações, cada qual com alguma alteração ou especificidade. Afinal, por que tantos padrões? Seriam tentativas de aprimoramento do espaço oferecido? O que teria levado a alterar cada um dos padrões? Quem teria refletido sobre as necessidades de alterações arquitetônicas? Educadores, crianças? Pais teriam sido ouvidos?

Das dez creches construídas até o ano que antecedeu o da Constituição de 1988, cinco foram edificadas seguindo o mesmo padrão arquitetônico, utilizado de 1983 a 1987. Pelas observações daquela pesquisa, o "padrão IPUF" foi o mais antigo. Ele foi assim denominado por essa pesquisadora por ser de responsabilidade do Instituto de Planejamento Urbano de Florianópolis (IPUF) (AGOSTINHO, 2003, p. 44). Das cinco creches construídas, três são localizadas na ilha e duas, na parte continental do município. Delimitando o foco deste estudo, tomaremos as creches implantadas nesse período e construídas sob o mesmo padrão arquitetônico - o “padrão IPUF”. Podemos capturar, através das realidades dessas cinco instituições de educação infantil, como os espaços (definidos pelos projetos arquitetônicos - planta baixa) foram sendo utilizados durante este período, uma vez que os projetos arquitetônicos, sua localização e os elementos físicos do exterior e interior "respondem a padrões culturais e pedagógicos que a criança internaliza e aprende" (VIÑAO FRAGO, 2001, p. 45). Teriam as mesmas configurações arquitetônicas modelado a organização do trabalho pedagógico junto às crianças nos diferentes bairros do município? Estas questões levam-nos a observar que, para além das 
histórias macro, pequenas histórias se constroem cotidianamente no interior das instituições e que, sem considerar cada uma delas, não seria possível constituir a história dessa rede de educação.

Considerando que "arquitetura envolve projeto, execução e uso" (GONÇALVES, 1996, p. 109), iniciamos a análise com as plantas arquitetônicas das instituições construídas pelo "padrão IPUF”, tendo nos padrões de configuração daqueles espaços projetados a possibilidade de evidenciar as singularidades da cultura material escolar do projeto. São estruturas simples e, segundo consta na pesquisa de Agostinho (2003), a elaboração dos projetos era realizada por técnicos de nível médio, não havendo registro quanto aos responsáveis por eles.

Como já observamos, a arquitetura não é neutra e deve ser considerada nos projetos educacionais. Partir desse campo de investigação significa adentrar na cultura material escolar, sob os pontos de vista da apropriação, da interpretação e da reinterpretação do espaço.

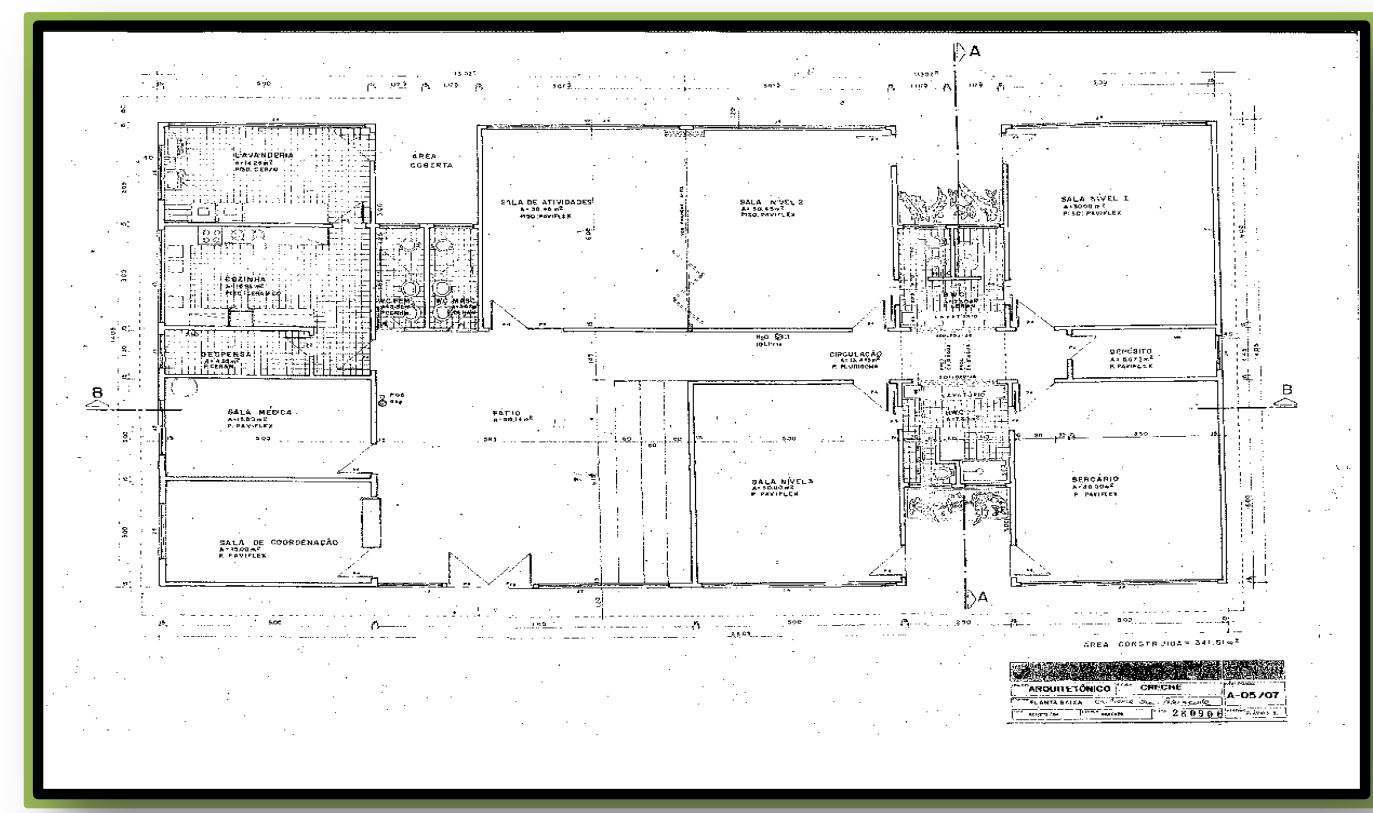

Figura 3 - Planta arquitetônica "padrão IPUF"

Fonte: Planta baixa pertencente ao acervo da prefeitura municipal de Florianópolis, cedida pela pesquisadora Kátia Adair Agostinho. 
A planta baixa evidencia a configuração interna do projeto. Por ela, analisamos tanto a distribuição como as escolhas dos espaços. Não nos deteremos em outras análises, embora caiba citar que a creche desse padrão tem uma fachada tão simples e despojada quanto a da velha igreja. O telhado, constituído de “duas águas”, lembra muito aquela edificação, não fosse o fato de essa de agora ser maior, ser de alvenaria e ter a cobertura de amianto. Embora sejam importantes, as fachadas podem apresentar a suntuosidade ou não do edifício, mas “constituem apenas a caixa dentro da qual está encerrada a joia arquitetônica. A caixa pode ser artisticamente trabalhada, ousadamente esculpida, $[\ldots]$, pode constituir uma obra-prima, mas continua sendo um invólucro [...]" (ZEVI, 2000, p. 20).

Nas cinco plantas “padrão IPUF”, identificamos a projeção dos seguintes espaços: banheiros para crianças e banheiros para adultos; cozinha; lavanderia; sala de direção; sala do médico; depósito; despensa; área coberta; salas de aula. Por essa identificação, constatamos haverem sido privilegiados espaços para as crianças, mas, com exceção do espaço do médico e do diretor, os outros adultos envolvidos nesse processo não foram considerados. Nessa distribuição, há escolhas e, sem dúvida, motivos para a existência ou inexistência de espaços específicos, ou para determinadas funções ou tarefas. Viñao Frago (2005) afirma que sua inexistência indicaria a pouca consideração ou a escassa importância. Por outro lado, a existência de determinados espaços, indica, de certa forma, a sua relevância inicial.

Ostetto (2000) observa que as crianças atendidas em 1979 também recebiam atendimento médico e odontológico. Sobre isso, a professora entrevistada relata que era preciso ir até a Ilha ${ }^{11}$ para receber esse tipo de atendimento. Ao que tudo indica, as novas edificações comportaram novas instalações como a sala do médico, em função das orientações do projeto inicial de 1976, que indicava a necessidade de "setor médico, odontológico, social”. Pode haver um contexto político-ideológico na determinação de tais escolhas, ainda não aprofundado. A pesquisa seguirá e nossa expectativa é de que as

\footnotetext{
${ }^{11}$ A ilha de Santa Catarina é parte do município de Florianópolis; situa-se no litoral sul do Brasil.
} 
plantas arquitetônicas e outros registros imagéticos, em diálogo com outros documentos, contribuam para entendermos os significados dessas escolhas.

\section{Algumas Considerações Finais}

Os reflexos dessa arquitetura nas práticas educativas materializadas no período estudado são contribuições para realizar uma interpretação da cultura escolar e para conferir sentido ao passado, tornando plausível, a partir do cruzamento das fontes, a escrita sobre a cultura material na trajetória das instituições para a infância, ao observar como aconteceu o uso do espaço, do mobiliário e como ocorreram, nessa trajetória histórica, as apropriações e reinterpretações pelos protagonistas.

Pelas imagens apresentadas, observam-se várias questões a serem consideradas sobre a ligação entre arquitetura e educação. Nessa linha de pensamento, para identificar distintas relações entre as duas atividades - arquitetura e educação -, nossa expectativa é de que outros registros imagéticos possam ajudar, tanto na observação da maneira como os espaços são ocupados, quanto na decifração das práticas educativas realizadas nessas instituições de educação infantil.

Entendendo que todas as ações realizadas com, para e junto às crianças devem ser consideradas num projeto educativo, e que tudo dentro de um espaço educacional forma e imprime uma identidade - seja a partir dos sujeitos envolvidos, seja da cultura escolar estabelecida -, a ideia é dar prosseguimento à pesquisa, documentando e investigando a arquitetura e o espaço escolar das instituições construídas, em diferentes bairros desse município, antes da Constituição federal de 1988. Isto significa ampliar a análise da história da educação infantil na Rede Municipal de Ensino Florianópolis, de forma a contribuir e a reforçar o que vários estudos têm apontado e o que os avanços legais têm procurado garantir: que as instituições de educação infantil sejam áreas que se destinem às crianças e que contemplem espaços e tempos para que vivam suas infâncias. 


\section{Fontes documentais}

BRASIL. Constituição (1988). Constituição [da] República Federativa do Brasil. Brasília, DF: Senado Federal.

Brasília.

. Lei Federal nº 8.069, de 13 de julho de 1990. Estatuto da Criança e Adolescente.

. Lei Federal n 9.394, de 20 de dezembro de 1996. Lei de Diretrizes e Bases da Educação. Brasília.

. (2004). Ministério da Educação. Secretaria de Educação Infantil e Fundamental.

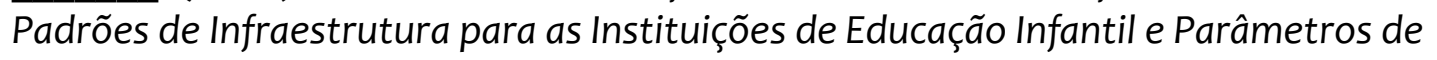
Qualidade para a Educação Infantil. Brasília. Documento Preliminar.

FLORIANÓPOLIS. Prefeitura Municipal de Florianópolis. Secretaria de Educação, Saúde e Assistência Social. Programa Educação Pré-Escolar no município de Florianópolis: Projeto Núcleos de Educação Infantil. 1976.

\section{Referências}

AGOSTINHO, K. A. O Espaço da Creche: que lugar é este? 2003. Dissertação (Mestrado em Educação) - Universidade Federal de Santa Catarina. Florianópolis.

BENCOSTTA, M. L. (2002). Memória e cultura escolar: a imagem fotográfica no estudo dos grupos escolares de Curitiba (1903-1971). In: CONGRESSO BRASILEIRO DE HISTÓRIA DA EDUCAÇÃO, 2. Anais... Natal: Offset Gráfica e Editora Ltda., v. 1, p. 21-31. Disponível em: http://www.sbhe.org.br/novo/congressos/cbhe2/-pdfs/Tema3/3154.pdf >. Acesso em: 20 ago. 2011.

CAMPOS, M. M. M. Pré-escola: entre a educação e o assistencialismo. In: Cad. Pesq., São Paulo (53): 21-24, mai. 1985.

DUSSEL, I. \& CARUSO, M. A invenção da sala de aula: uma genealogia das formas de ensinar. São Paulo: Moderna, 2003.

FARIA, Ana Lúcia G. O espaço físico como um dos elementos fundamentais para uma pedagogia infantil. In: FARIA, Ana Lúcia G. e PALHARES, Mariana (Orgs.). Educação infantil pós - LDB: rumos e desafios. Campinas: Autores associados, 4. ed., 2003. p. 67-100. 
GONÇALVES, R. de C. P. Arquitetura escolar: a essência aparece. Fábrica e escola confundem-se no desenho da Polivalente. 1996. Dissertação (Mestrado em Educação) CED/UFSC - Florianópolis.

JOLY, M. Introdução à análise da imagem. Campinas: Papirus, 1996.

KOSSOY, B. Fotografia e memória: a reconstituição por meio da fotografia. In: SEMAIN, E. (Org.). O fotográfico. São Paulo: Hucitec, 1998. p. 41-120.

KUHLMANN JR., M. Educação Infantil e Currículo. In: FARIA, A. L. G. e PALHARES, M. S. (orgs.). Educação Infantil Pós-LDB: Rumos e Desafios. São Paulo: Autores Associados, (2005), p. 51-65.

. Infância e educação infantil: uma abordagem histórica. Porto Alegre: Mediação,

2010

LAHOZ ABAD, P. El modelo froebeliano de espacio-escuela. Su introducción en España. Espanha, 1991. Historia de la Educación. In: Revista Interuniversitaria, n. 10, p. 107-134. Disponível em: http://dialnet.unirioja.es/servlet/autor?codigo=85259. Acesso em: 17 ago. 2011.

OLIVEIRA, Z. R. de. Educação Infantil: fundamentos e métodos. São Paulo: Cortez, 2002.

OSTETTO, L. E. Educação Infantil em Florianópolis. Florianópolis: Cidade Futura, 2000.

ROSEMBERG, F. A educação pré-escolar brasileira durante os governos militares. In: Cad. Pesq., São Paulo, n. 82, ago 1982. p. 21-30.

SOUZA, R. de F. Fotografias escolares: a leitura de imagens na história da escola primária. In: Educar em revista. Curitiba, n. 18, 2001. p. 75-101.

VINÃO FRAGO, A. Historia de la educación e historia cultural: posibilidades, problemas, cuestiones. In: Revista Brasileira de Educação. Campinas, SP, n. o, set./dez 1995. p. 63-82.

. \& ESCOLANO, A. Currículo, espaço e subjetividade: a arquitetura como programa. Rio de Janeiro: DP\&A, 2001.

. VIÑAO FRAGO, A. ESPAÇOS, USOS E FUNÇÕES: a localização e disposição física da direção escolar na escola graduada. In: BENCOSTTA, M. L. A. (Org.). História da Educação, arquitetura e Espaço Escolar. São Paulo: Cortez, 2005, p. $15-91$.

ZEVI, B. Saber ver a arquitetura. São Paulo: Martins Fontes, 2000. 
Universidade do Estado de Santa Catarina - UDESC Programa de Pós-Graduação em Educação - PPGE Revista Linhas Volume 14 - Número 26 - Ano 2013 revistalinhas@gmail.com

Recebido em: 15/11/2012 Aprovado em: 12/05/2013 